\title{
Psychological picture of manifest and latent carbon disulphide poisoning
}

\author{
HELENA HÄNNINEN \\ Institute of Occupational Health, Haartmaninkatu 1,'Helsinki 29, Finland
}

\begin{abstract}
Hänninen, H. (1971). Brit. J. industr. Med., 28, 374-381. Psychological picture of manifest and latent carbon disulphide poisoning. A battery of psychological tests was administered to 50 viscose workers with carbon disulphide $\left(\mathrm{CS}_{2}\right)$ poisoning, 50 viscose workers exposed to $\mathrm{CS}_{2}$ without known poisoning, and 50 workers not exposed to $\mathrm{CS}_{2}$. There were large and statistically significant differences between the group means of the poisoned and the unexposed group in most performances involving speed, vigilance, manual dexterity, and intelligence. The exposed group also showed impairment, but the changes were less severe. $\mathrm{CS}_{2}$ thus apparently affects the working capacity and sociability of exposed workers earlier than can be diagnosed by purely medical means.

The differences between the groups were further studied by discriminant function analysis. The poisoned group could be reliably discriminated from the unexposed group. Of the unexposed and poisoned subjects, $91 \%$ were correctly classified in the proper group. The exposed workers could not be discriminated from the poisoned subjects with the same reliability owing to the effects of latent $\mathbf{C S}_{2}$ poisoning in the former group.

Analysis of the discriminant functions further suggests that the syndromes of latent and manifest $\mathrm{CS}_{2}$ poisoning differ not only in intensity but also in quality. Clinically manifested poisoning is characterized by lowered vigilance, diminished intellectual activity, diminished rational control, retarded speed, and motor disturbances, whereas traits indicative of depressive mood, slight motor disturbances, and intellectual impairment are characteristic of latent poisoning. This syndrome is probably much more common than was hitherto believed.
\end{abstract}

Adverse effects of industrial poisons should be diagnosed as early as possible. This is particularly true for agents that may cause irreversible psychological and neurological changes. Among them, carbon disulphide $\left(\mathrm{CS}_{2}\right)$ is well known for its irreversible effects on the nervous system.

The neuropsychiatric syndrome of $\mathrm{CS}_{2}$ poisoning has been described by Lewey (1938) and Vigliani (1961), among others. Vigliani (1961) states that the picture of $\mathrm{CS}_{2}$ poisoning has changed due to improved hygienic conditions in industry and decreasing levels of $\mathrm{CS}_{2}$ exposure. Dramatic manic-depressive psychoses are nowadays rare; what we find is a slowly developing syndrome of poisoning with intellectual decline, stereotype behaviour, and a neurasthenic syndrome accompanied by depression.

Münchinger (1963) and Chalupa (1966) have demonstrated the value of psychological methods in industrial toxicology. At the Institute of Occupational Health in Helsinki, a study of the effects of $\mathrm{CS}_{2}$ has been in progress since 1963 (Hänninen, $1963,1966,1967)$. This study attempts to answer the following questions: What is the quality and the degree of mental changes in clinical $\mathbf{C S}_{2}$ poisoning? What is the functional significance of these disturbances, i.e., what are the practical effects, for example, on the working capacity? Do these changes occur among $\mathrm{CS}_{2}$ workers who feel healthy and have no 
clinical symptoms; if so, to what extent? How do the symptoms of 'latent' poisoning differ from those of diagnosed poisoning?

\section{Material and methods}

\section{The subjects}

The subjects were all workers at a viscose rayon factory. The sample consisted of three groups, each of 50 subjects. Group I included all those with clinical $\mathrm{CS}_{\mathbf{2}}$ poisoning. Group II comprised men without clinical symptoms but who had been exposed to $\mathrm{CS}_{2}$ for five years or more. Group III comprised men not exposed to $\mathrm{CS}_{\mathbf{2}}$.

The groups were similar in age, educational background, type of work, and length of employment time at the factory. They differed in exposure/non-exposure (groups I and II/group III) and in illness/health (group I/ groups II and III). Table 1 shows the age and the employment time of the three groups.

In order to control the independent variables, only subjects working in the same factory were included in the study. Nevertheless it turned out to be impossible to find groups completely without overlapping as far as exposure/ non-exposure and illness/health were concerned.

TABLE 1

Some Background Data of the Subjects

\begin{tabular}{|c|c|c|c|c|c|}
\hline \multirow{2}{*}{ Group } & \multirow{2}{*}{ No. } & \multicolumn{2}{|c|}{ Age $(y r)$} & \multicolumn{2}{|c|}{$\begin{array}{c}\text { Employment } \\
\text { time }(y r)\end{array}$} \\
\hline & & Mean & (Range) & Mean & (Range) \\
\hline $\begin{array}{l}\text { I (poisoned) } \\
\text { II (exposed) } \\
\text { III (unexposed) }\end{array}$ & $\begin{array}{l}50 \\
50 \\
50\end{array}$ & $\begin{array}{l}40 \cdot 5 \\
38 \cdot 3 \\
37 \cdot 9\end{array}$ & $\begin{array}{l}(23-52) \\
(25-50) \\
(25-50)\end{array}$ & $\begin{array}{r}9 \\
11 \\
13\end{array}$ & $\begin{array}{c}(0 \cdot 5-20)^{1} \\
(5-20) \\
(5-20)\end{array}$ \\
\hline
\end{tabular}

${ }^{1}$ Years at work before occurrence of poisoning.

Exposure to $\mathrm{CS}_{2}$ The average monthly $\mathrm{CS}_{2}$ values recorded in the contaminated parts of the factory varied from 60 to $132 \mathrm{mg} / \mathrm{m}^{3}$ during the years 1950 and 1959 . From 1960, the values were between 30 and $90 \mathrm{mg} / \mathrm{m}^{3}$. Several subjects were employed before 1950 . According to sporadic measurements the $\mathrm{CS}_{2}$ levels were considerably higher at that time. All the subjects in group I had been exposed to $\mathrm{CS}_{2}$ before the onset of illness, but not after it. The exposure time in group I ranged from six months to 20 years with a mean of nine years (Table 1 ).

The subjects in group II had been exposed to $\mathrm{CS}_{\mathbf{2}}$ for 5 to 20 years (Table 1). The exposure had been continuous with the exception of holidays; some jobs also involved regular changes to out-door work. Half of the workers in group III had occasionally been exposed to $\mathrm{CS}_{2}$, but the exposure had been neither intense nor continuous.

Symptoms of poisoning in various groups In group I the poisoning was diagnosed on the basis of a thorough clinical, neurological, otoneurological, and neuro- ophthalmological examination, inciuding electroencephalography and electromyography. In four cases the diagnosis was uncertain. Both acute and chronic cases were included. In 20 cases poisoning had been diagnosed less than a year before psychological testing, 15 cases had been known for one to four years, and another 15 had been diagnosed five or more years earlier.

The effects of poisoning showed a large variation. Thirty-eight patients were capable of regular work. Of them, 33 were still working in the same factory. Some could manage only in sheltered work.

All the men in group II considered themselves healthy, and the regular biannual physical check-up had not revealed a single case of poisoning among them. Twelve men could, however, report occasional mild symptoms, such as headache, pain in the limbs, tremor, and insomnia. A suspicion of mild poisoning had arisen in three cases. These men had, however, recovered completely.

Of the men in group III, four had shown transient symptoms of $\mathrm{CS}_{2}$ effect, several years before, in connexion with casual work in the contaminated areas.

\section{Methods}

Development of a battery of tests To start with, an extensive battery of tests was constructed. It covered clinical tests, known for their validity as indicators of psychological disturbances, and aptitude tests with a prognostic validity as to job success, established in previous investigations at the Psychological Department of the Institute of Occupational Health (Blanz, 1965). The battery was administered to groups II and III, and to 22 with $\mathrm{CS}_{\mathbf{2}}$ poisoning. The results of a comparison between the groups, and a factor analysis (Hänninen, 1966, 1967), made possible the construction of a reduced battery of tests, valid enough to discriminate between the groups and short enough to be applied at outpatient clinics. This battery was administered to the subjects in group I at the outpatient clinic of the Institute of Occupational Health.

The battery of tests included the following variables (the variable numbers and the abbreviations are the same as in Tables 2, 3, and 4):

\section{Intelligence test}

Five subtests from Wechsler adult intelligence scale (Wechsler, 1955):

Digit span

Variable (1, D Sp): raw score

Similarities

Variable (2, Sim): raw score

Block design

Variable (3, BD): raw score

Picture completion

Variable (4, PC): raw score

Digit symbol

Variable (5, D Sy): raw score

Other abilities test

Bourdon-Wiersma vigilance test (time limit $8 \mathrm{~min}$ )

Variables (6, BW speed): number of rows

(7, BW errors): number of errors

(8, BW fluctuation): time variation in completing a row 
Santa Ana dexterity test (Fleishman, 1954).

Variables (9, SA right): right-hand performance

(10, SA left): left-hand performance

(11, SA coo): coordination of both hands

Symmetry drawing

Variable (12, Sym): number of reversions

Benton visual retention test (Benton, 1961)

Variable (13, Benton): number of correct items

Personality test

Rorschach inkblot test (Rorschach, 1946; Klopfer,

Ainsworth, Klopfer, and Holt, 1954)

Variables (14, Ro Ada): adaptability

(15, Ro Emo): emotionality

(16, Ro Spon): spontaneity

(17, Ro Rat): rational self control

(18, Ro Orig): original intellectual activity

Psychomotor behaviour test

Mira test (Mira y López, 1965; Takala, 1953) Variables of extension and motor disturbances were included in the present study.

Variables (19, Mi I): length of lines

(20, Mi II): distance of lines

(21, Mi III): size of angles

(22, Mi IV): left-hand deviation

(23, Mi V): right-hand deviation

(24, Mi VI): form level of straight lines

(25, Mi VII): form level of broken lines

(26, Mi VIII): performance time

Detailed information of the tests and variables can be obtained from the author

Statistical methods The group differences were analysed using Student's $t$ test and multiple discriminant analysis (Cooley and Lohnes, 1962).

The discriminant analysis yields a variable combination with maximal group differences between means taking simultaneously into consideration standard deviations and intercorrelations. Discriminant analysis allows for a simple description of group differences and an allocation of weights to the variables included in the analysis. It is also a tool for a maximum likelihood classification of new subjects into groups on which the discrimination has been based. Discriminant function values can be calculated for each subject in the original sample as well as for new subjects. This makes it possible to decide to which group an individual is most likely to belong.

In the present study discriminant analysis was used in order to get a simple description of group differences and for obtaining diagnostic weights for the various tests; the discriminant function was not applied to new subjects.

Two analyses were made, one with the poisoned (group I) and the controls (group II), and another with all three groups. In both cases all the subjects of this study were classified according to their discriminant function values. In the first classification the subjects were classified as either 'healthy' or 'poisoned', and in the second the computer had to decide whether the subject was a healthy man, an exposed worker lacking in clinical symptoms, or a poisoned case.

The statistical analysis was carried out at Helsinki University Computing Centre according to the technique reported by Cooley and Lohnes (1962; pp. 116-145). The classification was based on Bayes' probabilities.

\section{Results \\ Differences in performance level}

The group means and standard deviations can be seen in Table 2. This also shows the probability of such results occurring by chance. We find clear differences between group I and group III in performances involving speed, vigilance, dexterity, and intelligence.

It might be somewhat unexpected to find that in certain respects group II was more like group I, the poisoned, than group III. This was, in particular, true of psychomotor and visual performance. The results indicate the presence of severe effects of $\mathrm{CS}_{2}$ exposure in clinically symptomless workers.

\section{Psychological characteristics of manifest and latent $\mathrm{CS}_{2}$ poisoning}

Differences between group I and group III Table 3 shows the discriminant function that gives the optimal differentiation between group I and group III. What seems to be typical of manifest $\mathbf{C S}_{2}$ poisoning is retarded speech, low vigilance, clumsiness and inaccuracy of motor functions, diminished intellectual activity, low level of spontaneous behaviour, and impoverished capacity of visualization.

Differences between the three groups In Table 4 we see the discriminant functions and the group means for the discriminant scores. The first function yields an optimal differentiation between group I and the other two. The function is similar in content to the one obtained for group I and group III. This can be interpreted as a confirmation of the profile typical of manifest $\mathrm{CS}_{2}$ poisoning, described above.

The second function discriminates between group II and the others. Workers exposed to $\mathrm{CS}_{2}$ but lacking in clinical symptoms show poor visual performance, normal verbal behaviour, impaired dexterity, disturbances in manual coordination, and low form level in the Mira test. Their Rorschach results can be interpreted to reflect good adjustment and rational control, on the one hand, but also diminished originality and spontaneity, on the other. Accurate and careful working style in the BourdonWiersma and Mira tests is also a characteristic of group II. This type of behaviour might be interpreted here as an indicator of depressive mood.

\section{Classification based on discriminant functions}

Classification into group I or group III According to the first discriminant analysis each subject was categorized as a member of either group I or group III on the basis of probability of membership. Table 5 shows the results: $94 \%$ of group III, the unexposed, were classified correctly, and $88 \%$ of group I. Nineteen of group II turned out to have a higher prob- 
TABLE 2

Means, Standard Deviations, and Significances between the Group Means

\begin{tabular}{|c|c|c|c|c|c|c|c|c|c|}
\hline \multicolumn{4}{|c|}{ Test } & \multicolumn{3}{|c|}{ Means and standard deviations } & \multicolumn{3}{|c|}{$\begin{array}{c}\text { Significances of } \\
\text { differences }(\mathrm{t} \text { tests) }\end{array}$} \\
\hline & & & & Group I & Group II & Group III & $I / I I$ & $I I I / I I$ & $I / I I I$ \\
\hline Intelligence & $\begin{array}{l}1 \\
2 \\
3 \\
4 \\
5\end{array}$ & $\begin{array}{ll}\text { D Sp } & \ldots \\
\text { Sim } & \ldots \\
\text { PC } & \ldots \\
\text { BD } & \ldots \\
\text { D Sy } & \ldots\end{array}$ & $\begin{array}{l}\ldots \\
\cdots \\
\cdots \\
\cdots \\
\cdots\end{array}$ & $\begin{array}{r}9.4 \pm 2.3 \\
14.8 \pm 5.2 \\
13.7 \pm 4.1 \\
32.5 \pm 9.4 \\
27.7 \pm 10.1\end{array}$ & $\begin{array}{r}9.3 \pm 1.4 \\
16.0 \pm 4.8 \\
14.1 \pm 2.5 \\
31.5 \pm 7.9 \\
33.3 \pm 9.5\end{array}$ & $\begin{array}{r}9.9 \pm 1.4 \\
15.5 \pm 4.4 \\
15.5 \pm 2.3 \\
35.7 \pm 7.2 \\
37.7 \pm 9.7\end{array}$ & $+t$ & $\begin{array}{l}+ \\
++ \\
++ \\
+\end{array}$ & $\begin{array}{l}++ \\
+++\end{array}$ \\
\hline Other abilities & $\begin{array}{r}6 \\
7 \\
8 \\
9 \\
10 \\
11 \\
12 \\
13\end{array}$ & $\begin{array}{l}\text { BW speed } \\
\text { BW errors } \\
\text { BW fluctuatio } \\
\text { SA right } \\
\text { SA left } \\
\text { SA coo } \\
\text { Sym .. } \\
\text { Benton }\end{array}$ & $\begin{array}{l}\ldots \\
\ldots \\
\text { on } \\
\cdots \\
\ldots \\
\cdots \\
\cdots \\
\ldots\end{array}$ & $\begin{array}{r}27.3 \pm 5.9 \\
22.2 \pm 16.8 \\
84.8 \pm 46.2 \\
39.1 \pm 9.2 \\
37.3 \pm 9.2 \\
23.5 \pm 7.6 \\
4.8 \pm 3.8 \\
19.7 \pm 3.0\end{array}$ & $\begin{array}{r}33.1 \pm 5.5 \\
17.8 \pm 15.6 \\
60.8 \pm 200 \\
44.7 \pm 7.1 \\
43.6 \pm 5.8 \\
26.0 \pm 6.0 \\
5.8 \pm 6.9 \\
20.9 \pm 2.9\end{array}$ & $\begin{array}{r}34.9 \pm \quad 5.9 \\
20.1 \pm 17.6 \\
58.0 \pm 18.2 \\
49.4 \pm 6.8 \\
48.2 \pm 6.4 \\
30.5 \pm 6.2 \\
3.6 \pm 5.0 \\
21.4 \pm 3.5\end{array}$ & $\begin{array}{l}++ \\
++ \\
+++ \\
+++\end{array}$ & $\begin{array}{l}+++ \\
+++ \\
+++\end{array}$ & $\begin{array}{l}+++ \\
+++ \\
+++ \\
+++ \\
+++ \\
+\end{array}$ \\
\hline Personality & $\begin{array}{l}14 \\
15 \\
16 \\
17 \\
18\end{array}$ & $\begin{array}{l}\text { Ro Ada } \\
\text { Ro Emo } \\
\text { Ro Spon } \\
\text { Ro Rat } \\
\text { Ro Orig }\end{array}$ & $\begin{array}{l}\cdots \\
\cdots \\
\cdots \\
\cdots \\
\cdots\end{array}$ & $\begin{array}{l}8.7 \pm 3.6 \\
9.8 \pm 4.2 \\
9.3 \pm 2.5 \\
8.5 \pm 2.6 \\
2.1 \pm 1.4\end{array}$ & $\begin{array}{r}10.7 \pm 3.8 \\
10.4 \pm 3.7 \\
10.0 \pm 3.6 \\
10.0 \pm 2.9 \\
3.0 \pm 2.3\end{array}$ & $\begin{array}{r}10.5 \pm 3.6 \\
11.5 \pm 3.5 \\
10.4 \pm 2.9 \\
9.6 \pm 2.8 \\
3.7 \pm 2.8\end{array}$ & $\begin{array}{c}++ \\
++ \\
+\end{array}$ & & $\begin{array}{c}+ \\
+ \\
+ \\
++\end{array}$ \\
\hline Psychomotor behaviour & $\begin{array}{l}19 \\
20 \\
21 \\
22 \\
23 \\
24 \\
25 \\
26\end{array}$ & $\begin{array}{l}\text { Mi I . } \\
\text { Mi II .. } \\
\text { Mi III .. } \\
\text { Mi IV .. } \\
\text { Mi V .. } \\
\text { Mi VI .. } \\
\text { Mi VII } \\
\text { Mi VIII }\end{array}$ & $\begin{array}{l}\ldots \\
\ldots \\
\ldots \\
\ldots \\
\ldots \\
\ldots \\
\ldots \\
\ldots\end{array}$ & $\begin{array}{l}3.5 \pm 1.1 \\
2.2 \pm 1.2 \\
2.5 \pm 1.1 \\
2.3 \pm 1.1 \\
2.2 \pm 1.0 \\
2.6 \pm 1.1 \\
2.5 \pm 1.2 \\
2.9 \pm 1.0\end{array}$ & $\begin{array}{l}3.1 \pm 1.2 \\
2.9 \pm 1.2 \\
3.3 \pm 0.9 \\
2.7 \pm 0.9 \\
2.8 \pm 1.2 \\
2.7 \pm 1.2 \\
2.5 \pm 0.8 \\
3.1 \pm 1.1\end{array}$ & $\begin{array}{l}3.0 \pm 1.0 \\
3.2 \pm 1.2 \\
3.0 \pm 1.0 \\
3.4 \pm 1.0 \\
3.3 \pm 1.1 \\
3.2 \pm 1.0 \\
3.2 \pm 1.2 \\
2.9 \pm 1.0\end{array}$ & $\begin{array}{c}++ \\
++ \\
+\end{array}$ & $\begin{array}{c}+++ \\
++ \\
+ \\
++\end{array}$ & $\begin{array}{c}+ \\
+++ \\
+ \\
+++ \\
+++ \\
++ \\
++\end{array}$ \\
\hline
\end{tabular}

ability of being a member of group I than of group III, i.e., $38 \%$ of the exposed lackıng in clinical symptoms were in their test results more like the poisoned subjects than the unafflicted ones.

Classification into group I, II or III The classification into three groups can be seen in Table 6. The number classified correctly was 113 , or $75 \%$. There were more misclassifications between groups II and III, and between II and I than between groups I and III. This can also be seen in the Figure with individuals plotted on a discriminant plane. Besides the misses, the Figure also reveals a number of borderline cases: some of the exposed are quite close to poisoned, and some of the poisoned are close to the exposed without clinical symptoms.

\section{Misclassifications}

Misclassifications can be attributed to chance, to the incomplete reliability of the discrimination scores, or to the insufficient discrimination power $3^{*}$ of the tests. Misclassified subjects, especially those with a high probability of belonging to a group other than their own, can also be individuals with a behaviour pattern atypical of that group. These subjects are also likely to be incorrectly diagnosed in clinical examinations. It is also possible that here some misclassifications can be attributed to an unsatisfactory initial categorization due to some overlapping on the criterion variable.

Next we take a closer look at the misclassified cases.

Group I subjects misclassified Three men of group I were classified into group III. Their test results were not typical of $\mathrm{CS}_{2}$ poisoning but, on the other hand, their discrimination scores also differed considerably from the average of group III. In the Figure we find these subjects in the least dense area of the discriminant space, which means that the behaviour of these men is not typical of any of the groups. One of the men had an atypical clinical record; another, 
TABLE 3

Discrimination ANALYSIS OF Groups I AND III

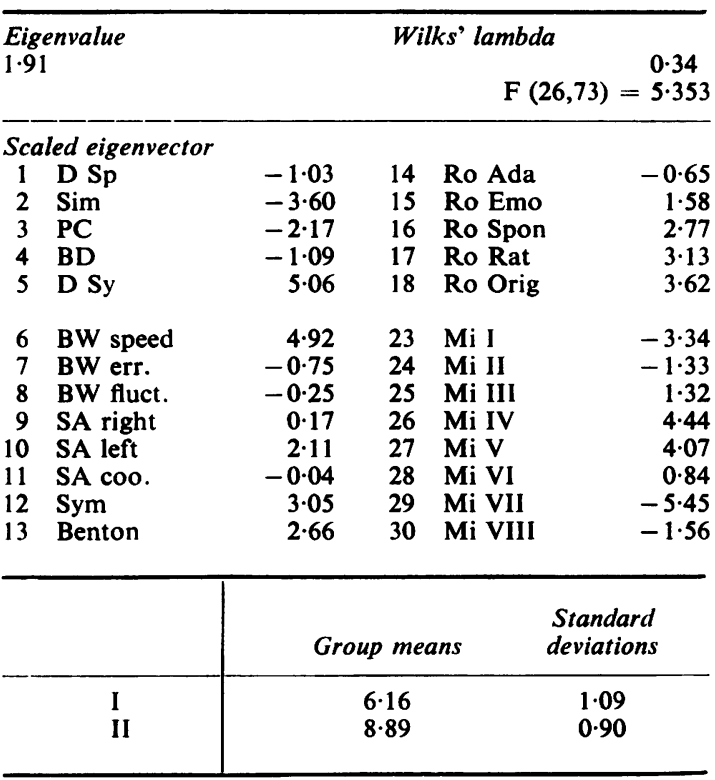

showing a variety of neurotic symptoms, had been categorized as poisoned on the basis of poly-neuropathy, and the third had suffered from an acute $\mathrm{CS}_{2}$ poisoning with exceptionally quick recovery.

Seven subjects of group I had been categorized as members of group II. In two cases the diagnosis was uncertain (two other workers with an uncertain diagnosis were classified into group I). The diagnosis of the remaining five was mild poisoning.

TABLE 5

Classification of Subjects into Groups I and III (ABSOLUTE FReQuenCIES)

\begin{tabular}{l|rrr|c}
\hline & \multicolumn{3}{|c|}{ Empirical group } & \multirow{2}{*}{ Total } \\
\cline { 2 - 4 } & I & II & III & \\
\hline Predicted group & 44 & 19 & 3 & 66 \\
I III & 6 & 31 & 47 & 84 \\
\hline & 50 & 50 & 50 & \\
\hline
\end{tabular}

TABLE 4

Discrimination ANalysis of Groups I, II, AND III

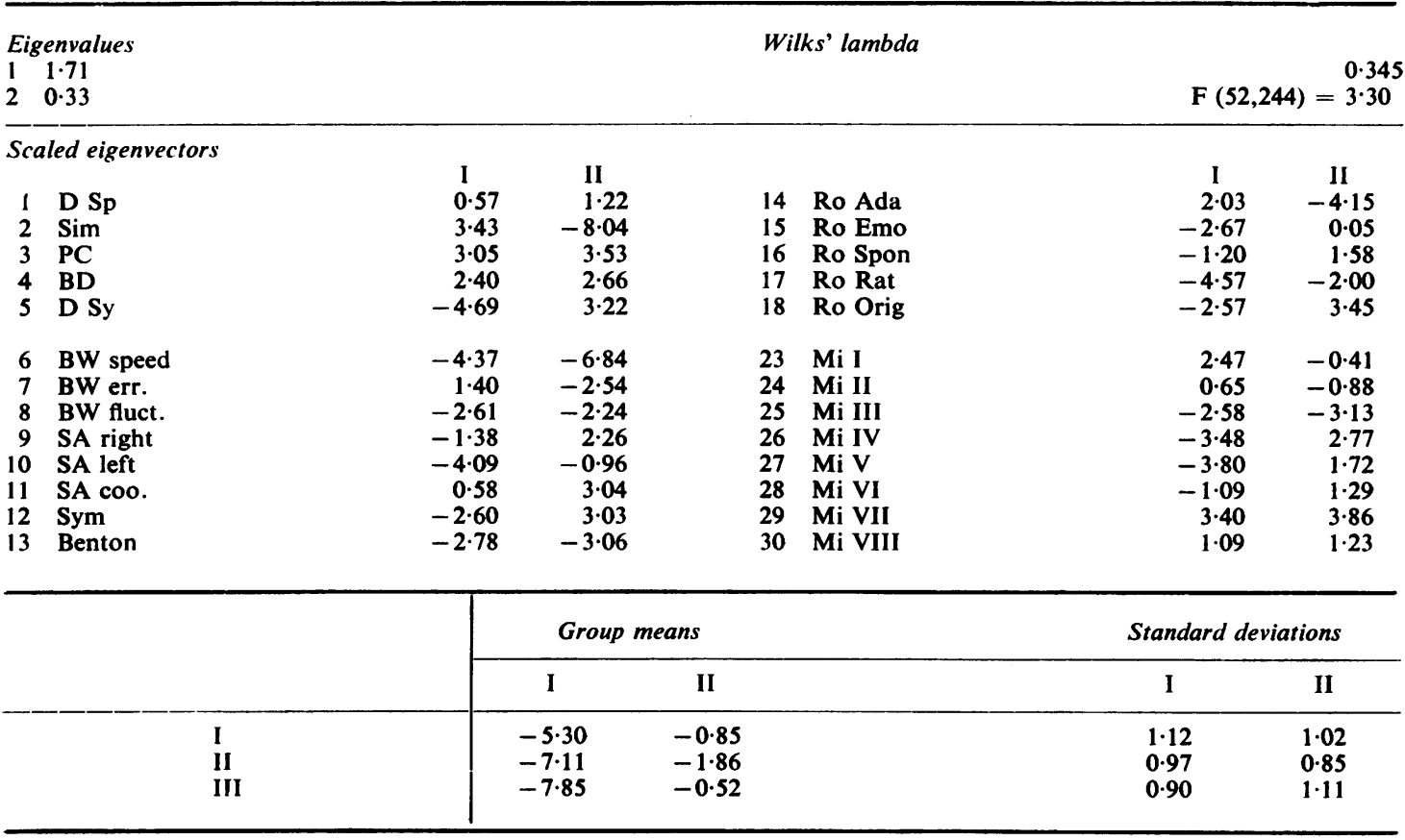


TABLE 6

Classification of Subjects into Groups I, II, and III (Absolute FrequenCIes)

\begin{tabular}{l|rrr|c}
\hline & \multicolumn{3}{|c|}{ Empirical group } & \multirow{2}{*}{ Total } \\
\cline { 2 - 3 } & I & II & III & \\
\hline Predicted group & & & & \\
I & 40 & 6 & 2 & 48 \\
II & 7 & 36 & 11 & 54 \\
III & 3 & 8 & 37 & 48 \\
\hline & 50 & 50 & 50 & \\
\hline
\end{tabular}

Group II subjects misclassified Eight subjects of group II were classified into group III. They had been exposed to $\mathrm{CS}_{2}$ for approximately the same time as the rest of group II.

Six men were classified into group I. One of them had left work after six months. He had complained of insomnia and headache, but no diagnosis of poisoning was made. Another was transferred to another job because of insomnia, fatigue, and anxiety. It might be possible that these men suffered from an undiagnosed poisoning, or that their behaviour was like that of the poisoned, though due to some other reasons.

Four subjects misclassified into group I have not shown any symptoms of illness, and they continue with their work.

Group III subjects misclassified Eleven subjects of group III were classified into group II. Four of them were repairmen who had been exposed occasionally to $\mathrm{CS}_{2}$; three workers had earlier been exposed for a year, and the remaining four had never been exposed. One must be careful in drawing conclusions because about half of those correctly classified had been exposed occasionally to $\mathbf{C S}_{2}$.

One of the two classified in group I had never been exposed, whereas the other one had been exposed occasionally. Both of them had always been considered healthy.

\section{Two special cases}

Two persons were tested twice, first when they were healthy and unexposed and later when they had been heavily exposed. In the first instance they belonged to the group of unexposed workers (group III). Later their working situation changed and they became exposed and were poisoned while repairing spinning machines; then they belonged to group I. The probabilities of their belonging to groups (Bayes probabilities) were as follows:

\begin{tabular}{c|ccc|ccc}
\hline \multirow{3}{*}{ Case } & \multicolumn{6}{|c}{ Probability } \\
\cline { 2 - 7 } & \multicolumn{3}{|c|}{ First testing } & \multicolumn{3}{|c}{ Second testing } \\
\cline { 2 - 7 } & I & II & III & I & II & III \\
\hline 1 & 0.07 & 0.08 & 0.85 & 0.98 & 0.02 & 0.00 \\
2 & 0.32 & 0.13 & 0.55 & 0.93 & 0.06 & 0.01 \\
& & & & & & \\
\hline
\end{tabular}

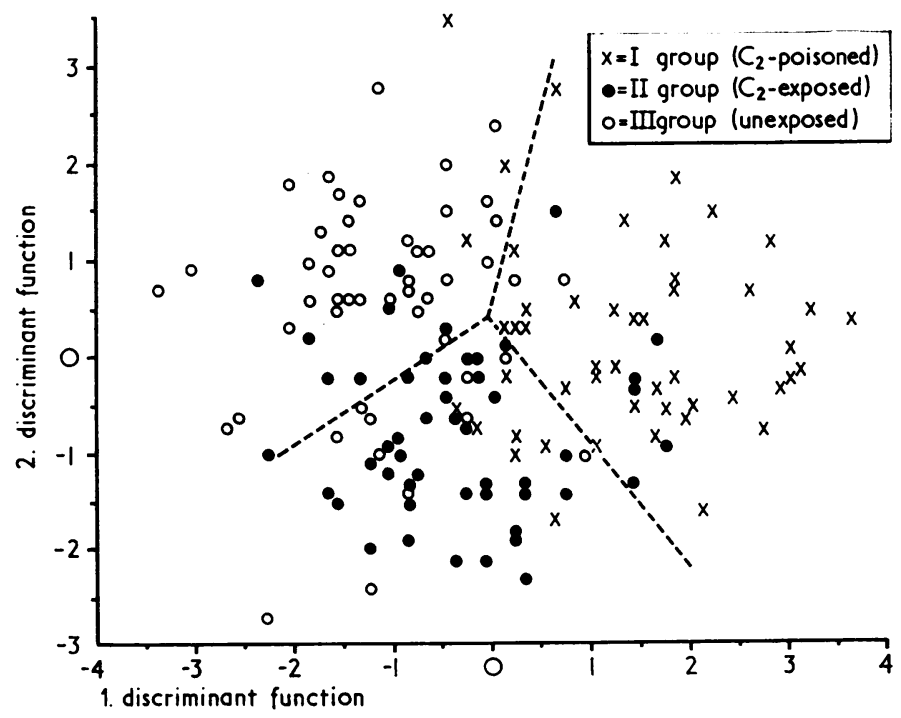

FIgure. Location of the individuals in the two discriminant plane (second analysis). 


\section{Discussion}

The psychological changes observed here in $\mathrm{CS}_{2}$ patients are consistent with previous clinical findings. A drop in the general performance level, diminished vigilance, low productivity and originality, and a loss of spontaneity have often been interpreted as signs of depression or mental retardation. An important finding of the present study is that a motor disturbance, often quite severe, is almost a regular concomitant of poisoning.

Earlier studies have focused on the subjective psychological symptoms of poisoning. The present results reveal, however, that the psychological syndrome of $\mathrm{CS}_{2}$ poisoning is not limited to the subjective experiences only. This syndrome also includes a disturbance of behaviour which affects working capacity, abilities in particular. We can observe a decline in intellectual performance. Even more serious disturbances occur in motor functions, in dexterity, and in alertness. As these abilities are essential for a factory worker's job success and working capacity (Blanz, 1965), it is obvious that the psychological disturbances due to $\mathrm{CS}_{2}$ are not only a subjective burden but also a severe handicap in everyday life. $\mathrm{CS}_{2}$ poisoning affects also human social behaviour. According to the present results, the damaging effect of $\mathrm{CS}_{2}$ is considerable: the mental dysfunction varies, but in general the effects seem to be more severe than was previously believed.

The defects found in 'healthy' workers exposed to $\mathrm{CS}_{2}$ are perhaps more disturbing. Disturbances and deterioration of functions essential for working capacity can be seen in them, too. What is important is that definite effects of $\mathbf{C S}_{2}$ are also present in men who have not been diagnosed as afflicted or have not even been suspected of being poisoned. They do not show impaired health or working capacity or personality changes to the same extent as those with manifest symptoms of poisoning, but a number of these men, some of them fairly young, show a considerable loss of mental capacity and potential.

The test profiles of the two afflicted groups, the exposed and the poisoned, were different. This might show that there are not only quantitative but also qualitative differences between early and later phases of $\mathrm{CS}_{2}$ poisoning. The discriminant function analysis provided additional information about 'latent' and 'manifest' $\mathrm{CS}_{2}$ syndromes. It is also possible that there were differences in intrinsic proneness to poisoning or in sensitivity to exposure between these two groups. Such a difference might explain why some workers developed clinical poisoning and some did not.

When the subjects were categorized, on the basis of the test results, into the various groups, the percentage of correct placements was 75 . The number of misclassifications between the poisoned and the unexposed was small. This shows that psychological tests are useful in diagnosing $\mathbf{C S}_{2}$ poisoning. Psychological testing should be included in periodic health examinations of exposed workers, as deterioration of mental functions appears to be more frequent and more severe than was hitherto believed.

The discriminant functions obtained here can hardly be universally applicable. There are differences in the average performance between ethnic and national groups, and probably also in the compensatory mechanisms that balance mental disturbances. This makes it necessary to revalidate the methods if they are to be applied in a different cultural environment from the present one.

It is probable that similar results can be obtained with other test combinations as well. What seems to be important is to make the battery of tests heterogeneous enough to cover a variety of mental functions. According to the discriminant function analysis, it is more reliable to base conclusions on the test profiles than on some isolated symptoms.

Dr. S. Hernberg is responsible for the diagnoses; I am grateful for his supportive interest and help in preparing the manuscript.

Thanks for help in the statistical analysis are due to Mr. J. Torppa at the Helsinki University Computing Centre.

I am also grateful to my colleagues at the Institute of Occupational Health, Helsinki, for their co-operation in gathering together the data for this study.

\section{References}

Benton, A. L. (1961). Der Benton-Test. Hans Huber, Berne. Blanz, F. (1965). Mixed standard scale, a new merit rating method. Helsinki Finlands Institute of Technology, Scientific Researches.

Chalupa, B. (1966). La recherche psychologique des intoxications par les substances neurotropes industrielles. Proc. 15th int. Congr. occup. Hlth, Suppl. III, pp. 27-30.

Cooley, W. W., and Lohnes, P. R. (1962). Multivariate Procedures for the Behavioral Sciences. Wiley, New York and London.

Fleishman, E. A. (1954). Dimensional analysis of psychomotor abilities. J. exp. Psychol. , 48, 437-454.

Hänninen, H. (1963). Psychische Symptome bei Schwefelkohlenstoffvergiftung. Proc. 14th int. Congr. occup. Hlth Madrid, Vol. II, pp. 894-897.

— (1966). Eine unter den arbeitern einer Rayonfiberfabrik vorgenommene Untersuchung. Proc. 15th int. Congr occup. Hlth, Vol. IV, pp. 309-312.

(1967). Psychological examination in carbon disulphide intoxication. In: Toxicology of Carbon Disulphide, edited by $\mathrm{H}$. Brieger and J. Teisinger, pp. 156-160. Excerpta Medica Foundation.

Klopfer, B., Ainsworth, M. D., Klopfer, W. G., and Holt, R. R. (1954). 2 vols. Developments in the Rorschach Technique. Harrap, New York.

Lewey, F. H. (1938). Survey of carbon disulphide and hydrogensulphide hazards in the viscose rayon industry. Penn. Dept. Labor and Ind. Bull, 46, Quoted by A. Hamilton and H. L. Hardy. Industrial Toxicology, pp. 404-407. Hoeber, New York, 1949. 
Mira y López, E. (1965). Myokinetische Psychodiagnostik. Hans Huber, Berne.

Münchinger, R. (1963). Der nachweis zentralnervöser Störungen bei lösungsmittelexponierten Arbeitern. Proc. 14th int. Congr. occup. Hlth, Madrid, Vol. II, pp. 687-689. Rorschach, H. (1946). Psychodiagnostik. Hans Huber, Berne. Takala, M. (1953). Studies of psychomotor personality tests. I. Ann. Sci. Fenn., Ser. B., 81, 2.
Wechsler, D. (1955). Wechsler Adult Intelligence Scale. Psychology Corporation, New York.

Vigliani, E. C. (1961). Erkrankungen durch Schwefelkohlenstoff. In: Handbuch der gesamten Arbeitsmedizin, edited by E. W. Baader, II, 1, pp. 313-325. Urban \& Schwarzenberg, Berlin.

Received for publication October 5, 1970.

\section{The July (1971) Issue}

Insulation workers in Belfast 1. Comparison of a random sample with a control population WILLIAM F. M. Wallace and Jean H. M. Langlands

Insulation workers in Belfast 2. Morbidity in men still at work Jean H. M. Langlands, William F. M. Wallace, and Marion J. C. Simpson

Insulation workers in Belfast 3. Mortality 1940-66 P. C. Elmes AND MARion J. C. Simpson

Nutritional and environmental studies on an ocean-going oil tanker

1. Thermal environment K. J. Collins, T. P. Eddy, D. E. Lee, and P. G. Swann

Nutritional and environmental studies on an ocean-going oil tanker

2. Heat acclimatization and nutrient balances K. J. Collins, T. P. Eddy, A. Hibbs, A. L. Stock, AND E. F. WHEELER

Thermal limits for industrial workers C. R. BeLl AND A. J. WATTS

An epidemiological study of lens opacities among steel workers J. WALlace, P. M. SWeEtNAm, C. G. WARner, P. A. Graham, and A. L. Cochrane

A comparison of some methods of diagnosing Raynaud phenomena of occupational origin B. HELLSTRøM AND K. MYHRE

An Australian study of telegraphists' cramp DAVID Ferguson

Evaluation of the psychophysiological functions in humans exposed to the 'Threshold Limit Value' of 1,1,1trichloroethane M. SALVINI, S. BinASCHI, AND M. Riva

Evaluation of the psychophysiological functions in humans exposed to trichloroethylene M. SALVINI, S. BINASCHI, AND M. RIVA

Haematological effects of chronic benzene poisoning in 217 workers MuZAFfer AKsoy, Koray Dinçol, Turhan AKgüN, Sakir ERdem, AND GüNCAG Dinçol

Prick-tests and serological tests in the diagnosis of allergic reactivity to enzymes used in washing products M. J. How AND G. W. CAMBRIDGe

Metallic mercury induced tremor in rabbits and mercury content of the central nervous system KATSUHIRO FUKUDA

Book reviews

A number of copies are still available and may be obtained from the Publishing Manager, British Medical Association, Tavistock Square, London WC1H 9JR price $£ 1.25$ ( $£ 1.5$ in countries overseas: U.S.A. \$3.60). 